\title{
An IF-DEMATEL-AHP based on Triangular Intuitionistic Fuzzy Numbers (TIFNs)
}

\author{
Razieh Keshavarzfard $^{\mathrm{a}^{*}}$ and Ahmad Makui ${ }^{\mathrm{b}}$
}

${ }^{a}$ Department of Industrial Engineering, South Tehran Branch, Islamic Azad University, Tehran, Iran ${ }^{b}$ Department of Industrial Engineering, Iran University of Science and Technology, Tehran, Iran

\begin{tabular}{|c|c|}
\hline CHRON I C LE & AB S T RACT \\
\hline $\begin{array}{l}\text { Article history: } \\
\text { Received July } 10,2014 \\
\text { Accepted November } 14,2014 \\
\text { Available online } \\
\text { November } 142014 \\
\text { Keywords: } \\
\text { AHP } \\
\text { Intuitionistic fuzzy sets } \\
\text { Preference relations } \\
\text { DEMATEL }\end{array}$ & $\begin{array}{l}\text { In the present paper, a novel intuitionistic fuzzy Multiple Attribute Decision Making (MADM) is } \\
\text { proposed for modelling and solving analytical hierarchy process (AHP) problems with small amount } \\
\text { of relationship among various criteria. Assigning a membership degree, fuzzy sets can model some } \\
\text { uncertainty to the decision space. Intuitionistic fuzzy sets model the uncertainty more accurately } \\
\text { associated with both membership and non-membership degree. Based on advantages of Intuitionistic } \\
\text { fuzzy sets, this paper first uses IF-AHP to evaluate the weighting for each criterion and then develops } \\
\text { an intuitionistic fuzzy DEMATEL method to establish contextual relationships among those criteria. } \\
\text { Finally, an integrated IF-DEMATEL-AHP method is proposed and used for a case study for } \\
\text { selecting managers in the automobile industry in Iran. }\end{array}$ \\
\hline
\end{tabular}

(c) 2015 Growing Science Ltd. All rights reserved.

\section{Introduction}

The Analytical Hierarchy Process(AHP) developed by Saaty(1980) possesses distinct advantage of dealing with subjective information of Decision Makers (DMs). AHP can be used in several areas such as selection, evaluation, planning and development, decision making, forecasting, etc. Pair-wise comparison makes it easy to express DM's preferences and meanwhile consistent ratios insure the validity of judgments. The pair-wise comparison methods are based on crisp real numbers while DM's assessments in pair-wise comparison always handle uncertainty in reality so that DM's could sometimes feel more confident to provide fuzzy judgment than crisp comparisons (Wang \& Chen, 2008). Atanassov (1986) extended the concept of Zadeh's fuzzy sets (Zadeh, 1965) and introduced Intuitionistic Fuzzy Sets (IFSs), whose prominent characteristic is that it assigns to each element a membership degree and a nonmembership degree. It gives a powerful tool to handle uncertainty in real-world case studies especially when to express a pair-wise comparison. In some studies, therefore, IFS is applied for pair-wise comparison matrix and refers to it as Intuitionistic Fuzzy Comparison Matrix (IFCM) or Intuitionistic Fuzzy Preference Relation (IFPR) (Xu, 2007). In these studies, the causal interrelationship among the criteria is disregarded. However, the criteria may influence on * Corresponding author.

E-mail address: st r keshavarzfard@azad.ac.ir (R. Keshavarzfard)

(C) 2015 Growing Science Ltd. All rights reserved. doi: $10.5267 /$ j.dsl.2014.11.002 
each other in many multi attribute decision making (MADM) problems. We require additional techniques to handle this problem. There are some methods to measure the level of causal relationship among the criteria in the literature. DEMATEL is one of the most popular techniques for this purpose and it is originated from the Geneva Research Centre of the Battelle Memorial Institute. This method is especially pragmatic to visualize the structure of complicated causal relationships (Buyukozkan \& Cifci, 2011). In DEMATEL, the criteria are divided into two groups; the cause group and the effect group. The cause group influences on the effect group where such effect is used to estimate the criteria weights (Dalalah et al., 2011). DEMATEL is a comprehensive technique for constructing and analyzing astructural model involving causal relationships among complex factors (Buyukozkan \& Cifci, 2011). DEMATEL gathers collective knowledge to capture the causal relationships between strategic criteria (Jassbi et al., 2011). There are some studies where DEMATEL is successfully used in the literature (Chang et al., 2011; Lin \& Wu, 2008; Tseng, 2009; Wu \& Lee, 2007). Some modifications have also been made by some researchers to express vagueness in DEMATEL method. For instance, Dalalah et al. (2011) modified the method by expressing the effect comparisons of the factors in terms of linguistic variables. In such case, the executive people can assess the influence relationship among the factors with linguistic terms (Baykasoğlu et al., 2013).

In this study, a new approach named IF-AHP-DEMATEL is proposed, in which IF-DEMATEL is introduced to represent the correlation among the criteria in an intuitionistic fuzzy enviornment. The proposed IF-DEMATEL uses triangular intuitionistc fuzzy numbers to find weights. The reminder of this paper is organized as follows. In section 2, a review of intuitionistic fuzzy sets is given. Section 3 presents an IF-AHP and then An IF-DEMATEL is developed. In section 4, a proposed hybrid model is implemented in a case study in Iran. Finally a brief conclusion is given in Section 5.

\section{Review of Intuitionistic Fuzzy Sets(IFS)}

Let $X$ be a universe of discourse. A fuzzy set $A=\left\{\left(x, \mu_{A}(x)\right) \mid x \in X\right\}$ defined by Zadeh (1965) is characterized by a membership function $\mu_{A}(x): X \rightarrow[0,1]$, where $\mu_{A}(x)$ denotes the degree of membership of the element $x$ to the set $A$. Atanassov (1986) introduced a generalized fuzzy set called intuitionistic fuzzy set, shown as follows:

$\mathrm{A}=\left\{\left(\mathrm{x}, \mu_{\mathrm{A}}(\mathrm{x}), \mathrm{v}_{\mathrm{A}}(\mathrm{x})\right) \mid \mathrm{x} \in \mathrm{X}\right\}$

which is characterized by a membership function $\mu_{A}(x): X \rightarrow[0,1]$ and a non-membership function $\mathrm{v}_{\mathrm{A}}(\mathrm{x}): \mathrm{X} \rightarrow[0,1]$ with the condition $\forall \mathrm{x} \in \mathrm{X}: \mu_{\mathrm{A}}(\mathrm{x})+\mathrm{v}_{\mathrm{A}}(\mathrm{x}) \leq 1$, where the numbers $\mu_{\mathrm{A}}(\mathrm{x})$ and $\mathrm{v}_{\mathrm{A}}(\mathrm{x})$ represent, respectively, the degree of membership and the degree of non-membership of the element $x$ to the set A. Denotation $\pi_{A}(x)=1-\mu_{A}(x)-v_{A}(x)$ represents the degree of hesitation or intuitionistic index or non-determinacy of $x$ to $A$. Therefore, for ordinary fuzzy sets, the degree of hesitation is $\pi_{A}(x)=0$. The ordered pair $\alpha_{A}(x)=\left(\mu_{\alpha}(x), v_{\alpha}(x)\right)$ is referred to as an $\operatorname{IFV}(X u, 2007)$, where, $\mu_{\alpha}(x), v_{\alpha}(x) \in[0,1]$ and $\mu_{\alpha}(x)+v_{\alpha}(x) \leq 1$. Associated with the degree of hesitation, an IFV can also be equivalently stated by $\alpha(\mathrm{x})=\left(\mu_{\alpha}(\mathrm{x}), \mathrm{v}_{\alpha}(\mathrm{x}), \pi_{\alpha}(\mathrm{x})\right)$ where $\mu_{\alpha}(\mathrm{x}), \mathrm{v}_{\alpha}(\mathrm{x}), \pi_{\alpha}(\mathrm{x}) \in[0,1]$ and $\mu_{\alpha}(\mathrm{x})+\mathrm{v}_{\alpha}(\mathrm{x})+\pi_{\alpha}(\mathrm{x})=1$.

Now consider two triangular IFS $A$ and $B$ in Fig. 1. These triangular IFS can be written as $A=$ $\left\langle\left[\left(a_{1}^{\prime}, b_{1}^{\prime}, c_{1}^{\prime}\right) ; \mu_{A}\right],\left[\left(a_{1}, b_{1}, c_{1}\right) ; v_{A}\right]\right\rangle$ and $B=\left\langle\left[\left(a_{2}^{\prime}, b_{2}^{\prime}, c_{2}^{\prime}\right) ; \mu_{B}\right],\left[\left(a_{2}, b_{2}, c_{2}\right) ; v_{B}\right]\right\rangle$. Three vertices of triangular IFS represented by $\left(a_{i}^{\prime}, b_{i}^{\prime}, c_{i}^{\prime}\right)$ and $\left(a_{i}, b_{i}, c_{i}\right)$ are defined over a universe of discourse $X$. The three vertices represent minimum, most likely and maximum values over $X$. Membership $\mu_{x}$ and nonmembership functions $v_{x}$ belong to the most likely values in triangular IFS, i.e., $b_{i}^{\prime}$ and $b_{i}$, respectively. Four common arithmetic operations for intuitionistic fuzzy sets, addition subtraction, multiplication and division, are demonstrated using the triangular IFS A and B (Saaty \& Shih, 2009). 
2.1. Addition $(A+B)$ :

$$
\begin{aligned}
A+B= & \left\langle\left[\left(a_{1}^{\prime}, b_{1}^{\prime}, c_{1}^{\prime}\right) ; \mu_{A}\right],\left[\left(a_{1}, b_{1}, c_{1}\right) ; v_{A}\right]\right\rangle+\left\langle\left[\left(a_{2}^{\prime}, b_{2}^{\prime}, c_{2}^{\prime}\right) ; \mu_{B}\right],\left[\left(a_{2}, b_{2}, c_{2}\right) ; v_{B}\right]\right\rangle \\
& =\left\langle\left[\left(a_{1}^{\prime}+a_{2}^{\prime}, b_{1}^{\prime}+b_{2}^{\prime}, c_{1}^{\prime}+c_{2}^{\prime}\right) ; \min \left(\mu_{A}, \mu_{B}\right)\right],\left[\left(a_{1}+a_{2}, b_{1}+b_{2}, c_{1}+c_{2}\right) ; \max \left(v_{A}, v_{B}\right)\right]\right\rangle
\end{aligned}
$$

\subsection{Subtraction $(A-B)$ :}

$$
\begin{aligned}
A-B & =\left\langle\left[\left(a_{1}^{\prime}, b_{1}^{\prime}, c_{1}^{\prime}\right) ; \mu_{A}\right],\left[\left(a_{1}, b_{1}, c_{1}\right) ; v_{A}\right]\right\rangle-\left\langle\left[\left(a_{2}^{\prime}, b_{2}^{\prime}, c_{2}^{\prime}\right) ; \mu_{B}\right],\left[\left(a_{2}, b_{2}, c_{2}\right) ; v_{B}\right]\right\rangle \\
& =\left\langle\left[\left(a_{1}^{\prime}-c_{2}^{\prime}, b_{1}^{\prime}-b_{2}^{\prime}, c_{1}^{\prime}-a_{2}^{\prime}\right) ; \min \left(\mu_{A}, \mu_{B}\right)\right],\left[\left(a_{1}-c_{2}, b_{1}-b_{2}, c_{1}-a_{2}\right) ; \max \left(v_{A}, v_{B}\right)\right]\right\rangle
\end{aligned}
$$

2.3. Multiplication $(A \times B)$ :

$$
\begin{aligned}
A \times B= & \left\langle\left[\left(a_{1}^{\prime}, b_{1}^{\prime}, c_{1}^{\prime}\right) ; \mu_{A}\right],\left[\left(a_{1}, b_{1}, c_{1}\right) ; v_{A}\right]\right\rangle \times\left\langle\left[\left(a_{2}^{\prime}, b_{2}^{\prime}, c_{2}^{\prime}\right) ; \mu_{B}\right],\left[\left(a_{2}, b_{2}, c_{2}\right) ; v_{B}\right]\right\rangle \\
& =\left\langle\left[\left(a_{1}^{\prime} \times a_{2}^{\prime}, b_{1}^{\prime} \times b_{2}^{\prime}, c_{1}^{\prime} \times c_{2}^{\prime}\right) ; \min \left(\mu_{A}, \mu_{B}\right)\right],\left[\left(a_{1} \times a_{2}, b_{1} \times b_{2}, c_{1} \times c_{2}\right) ; \max \left(v_{A}, v_{B}\right)\right]\right\rangle
\end{aligned}
$$

\subsection{Division $(A / B)$ :}

$$
\begin{aligned}
A / B & =\left\langle\left[\left(a_{1}^{\prime}, b_{1}^{\prime}, c_{1}^{\prime}\right) ; \mu_{A}\right],\left[\left(a_{1}, b_{1}, c_{1}\right) ; v_{A}\right]\right\rangle /\left\langle\left[\left(a_{2}^{\prime}, b_{2}^{\prime}, c_{2}^{\prime}\right) ; \mu_{B}\right],\left[\left(a_{2}, b_{2}, c_{2}\right) ; v_{B}\right]\right\rangle \\
& =\left\langle\left[\left(a_{1}^{\prime} / c_{2}^{\prime}, b_{1}^{\prime} / b_{2}^{\prime}, c_{1}^{\prime} / a_{2}^{\prime}\right) ; \min \left(\mu_{A}, \mu_{B}\right)\right],\left[\left(a_{1} / c_{2}, b_{1} / b_{2}, c_{1} / a_{2}\right) ; \max \left(v_{A}, v_{B}\right)\right]\right\rangle
\end{aligned}
$$

\section{IF-AHP-DEMATEL}

The proposed IF-AHP-DEMATEL approach is depicted step by step as follows:

\subsection{Intuitionistic fuzzy analytic hierarchy process (IF-AHP) method}

A hierarchy is a powerful manner of classification used to order information gained either from experience or from our own thinking. Thus, the complexity of the world around us could be understood according to the order and distribution of influences, which makes certain outcomes happen (Saaty \& Shih, 2009). Due to the confinement of the ability of expressing a judgment accurately and advantage of IFS in considering both degree of membership and degree of nonmembership at the same time, IFS is introduced to the traditional AHP.

\section{Step 1. Develop a hierarchical structure.}

DMs could structure hierarchies following advices by Saaty and Shih (2009). Suppose, there are $n$ levels in the hierarchical structure, in which the top level is named as the first level and the last level or the alternatives level as the nth level, there are $n_{i}$ elements or criteria in the ith level, where the elements are denoted by $\left\{e_{1}^{i}, \ldots, e_{n_{i}}^{i}\right\}, i=1, \ldots, n$. Note that $n_{1}=1$ (Wang et al., 2011).

Step 2. Develop pairwise comparisons using intuitionistic fuzzy judgment matrix (Sadiq \& Tesfamariam, 2009):

Intuitionistic fuzzy judgment matrix $(\overline{\bar{J}})$ is generated using pairwise comparisons $\left(\overline{\bar{J}}_{i j}\right)$. For instance, for a pairwise comparison between $C_{1}$ and $C_{2}$, assume that a decision maker assigns a weak importance(Table 1), i.e., " $\mathrm{C}_{2}$ is three times more important than $\mathrm{C}_{1}$ ", In F-AHP, instead of a "crisp" value of 3 (as in standard AHP), a Triangular Fuzzy Number(TFN) expressed by three vertices $(a, b, c)$ can be used. The vertices of the TFN correspond to (minimum, most likely, maximum) values over the universe of discourse $X$ (on the scale of 1-9). Therefore, the weak importance in case of F-AHP refers to a value, say, between 2.5 and 3.5 with the most likely value being 3 , so for example fuzzy pairwise comparison can be written as a vector $(2.5,3,3.5)$. To generalize this concept, the vagueness is expressed using a fuzzification factor $\Delta^{\mu}$. Therefore, the above pairwise comparison can be generalized as $\left(3-\Delta^{\mu}, 3,3+\Delta^{\mu}\right)$, where $\Delta^{\mu}=0.5$ is assumed. The 
minimum and the maximum values of a pairwise comparison have membership value of zero and the most likely value has a membership of 1 . During the evaluation, in addition to vagueness, the decision maker can specify his/her degree of belief for the pairwise comparisons.

Assume that the decision maker's belief is $80 \%$ for his/her evaluation of weak importance. This belief is represented by a membership function $\mu_{x}=0.8$, i.e., a subnormal fuzzy set. Therefore, the lower bound of triangular IFS can be written as $\left[\left(3-\Delta^{\mu L}, 3,3+\Delta^{\mu L}\right) ; \mu_{x}=0.8\right]$. We assume that the decision-maker does not provide any further information about his degree of non-belief about this evaluation. Therefore, for triangular IFS, the non-membership function $v_{x}$ is assumed to be zero and the upper bound membership is $1-v_{x}=1.0$. This refers to normal fuzzy set. Similarly, a fuzzification factor $\Delta^{\mu U}$ is introduced, which may or may not have the same value as $\Delta^{\mu L}$. Therefore, a pairwise comparison of weak importance in terms of triangular IFS can be written as $\overline{\overline{3}}$. The upper and lower bounds of memberships can be determined from triangular IFS at any point over the universe of discourse, i.e., $\overline{\overline{3}}=\left\langle\left[\left(3-\Delta^{\mu \mathrm{L}}, 3,3+\Delta^{\mu \mathrm{L}}\right) ; \mu_{\mathrm{x}}=0.8\right],\left[\left(3-\Delta^{\mu \mathrm{U}}, 3,3+\Delta^{\mu \mathrm{U}}\right) ; \mathrm{v}_{\mathrm{x}}=0\right]\right\rangle$. Therefore, at the most likely value, i.e., 3 , the interval-valued membership is $[0.8,1]$. At any other point in the IFS, this interval-valued membership is determined from two nested triangles. Therefore, for $n$ criteria, the intuitionistic fuzzy judgment matrix $\overline{\bar{J}}$ can be written as:

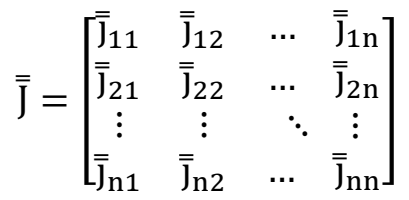

For diagonal entries $i=j, \overline{\overline{\mathrm{J}}}_{\mathrm{ij}}=1$. Upper right-hand triangle entries $\overline{\overline{\mathrm{j}}}_{\mathrm{ij}}$ are pairwise comparisons that need to bedefined by a decision maker, whereas lower left-hand triangle entries are derived taking a reciprocal, i.e., $\overline{\overline{\mathrm{J}}}_{\mathrm{ji}}=1 / \overline{\mathrm{J}}_{\mathrm{ij}}$.

Table 1

Linguistic measures of importance (Saaty 1980)

\begin{tabular}{lcccccc}
\hline $\begin{array}{l}\text { Relative } \\
\text { importance }\end{array}$ & $\begin{array}{l}\text { Equal } \\
\text { importance }\end{array}$ & $\begin{array}{l}\text { Weak } \\
\text { importance }\end{array}$ & $\begin{array}{l}\text { Essential or } \\
\text { strong } \\
\text { Importance }\end{array}$ & $\begin{array}{l}\text { Demonstrated } \\
\text { Importance }\end{array}$ & $\begin{array}{l}\text { Extreme } \\
\text { importance }\end{array}$ & $\begin{array}{l}\text { Intermediate values Between two } \\
\text { Adjacent judgments }\end{array}$ \\
\hline Importance degree & 1 & 3 & 5 & 7 & 9 & $2,4,6,8$ \\
\hline
\end{tabular}

\section{Step 3: Check for consistency}

Often, the pairwise comparisons in the judgment matrix are subjected to inconsistency. For example, in a pairwise comparison, if we say $A / B=2, A / C=4$, therefore it implies that $B / C=2$. However, if the pairwise comparison, $\mathrm{B} / \mathrm{C} \neq 2$, there is an apparent inconsistency. The AHP utilizes consistency index (CI) and consistency ratio(CR)to discern if there is any inconsistency in the fuzzy judgment matrix $\overline{\bar{J}}$. The threshold of the $\mathrm{CR}$ is $10 \%$. For brevity, the calculation procedures are not presented in his paper.

\section{Step 4: Calculate the intuitionistic fuzzy set weights}

Different techniques can be implemented to compute the final IF weights, such as, computation of the eigenvector, arithmetic mean, and geometric mean. Preliminary investigation carried out the authors showed no significant difference. Consequently, for simplicity, the geometric mean is applied to compute the intuitionistic fuzzy weights (Sadiq \& Tesfamariam, 2009). For each row $\overline{\overline{\mathrm{j}}}_{\mathrm{i}}$ first taking the geometric mean, and then normalizing it leads to intuitionistic fuzzy weights $\overline{\mathrm{w}}_{\mathrm{i}}(\mathrm{i}=1$ to $\mathrm{n})$ : 
$\overline{\overline{\mathrm{j}}}_{\mathrm{i}}=\left(\overline{\overline{\mathrm{J}}}_{\mathrm{i} 1} \otimes \ldots \otimes \overline{\overline{\mathrm{j}}}_{\mathrm{in}}\right)^{1 / n}$

$\overline{\overline{\mathrm{w}}}_{\mathrm{i}}=\overline{\overline{\mathrm{j}}}_{\mathrm{i}} \otimes\left(\overline{\overline{\mathrm{j}}}_{\mathrm{i} 1} \oplus \ldots \oplus \overline{\overline{\mathrm{j}}}_{\mathrm{in}}\right)^{-1}$

\subsection{The IF-DEMATEL method}

DEMATEL was developed to study the structural relations in the complex system (Chou et al., 2012). The IF- DEMATEL is described below:

Step 1: Selecting the committee of experts who have experienced about this research issue.

We should set the decision goal and set up a committee.

\section{Step 2: Developing the criteria and designing the fuzzy linguistic scale.}

The committee should follow our proposed method with the steps. First, they should define the decision goals and develop the criteria about the research question. Linguistic variables take on values defined in its term set - its set of linguistic terms. Here, we use this kind of expression to compare criteria by four basic linguistic terms, as "Very high influence", "High influence", "Low influence" and "Very low influence" with respect to a intuitionistic fuzzy level scale as Table 2.

Table 2

Linguistic scales for the importance

\begin{tabular}{cc}
\hline Linguistic terms & Linguistic values \\
\hline Very high influence(VH) & $(7.5,8,8.5 ; 7,8,9)$ \\
High influence(H) & $(5.5,6,6.5 ; 5,6,7)$ \\
Low influence(L) & $(3.5,4,4.5 ; 3,4,5)$ \\
Very low influence(VL) & $(1.5,2,2.5 ; 1,2,3)$ \\
No influence(No) & $(1,1,1 ; 1,1,1)$ \\
\hline
\end{tabular}

\section{Step 3: Generating the assessments of decision-makers.}

To measure the relationships between the factors which are demonstrated by the $F=\left\{F_{i} \mid i=\right.$ $1, \ldots, n\}$, the experts were asked to make sets of pairwise comparison. Then the $\tilde{z}_{(1)}, \tilde{z}_{(2)}, \ldots, \tilde{z}_{(n)}$ can be obtained (Chou et al., 2012). IF matrix $\tilde{z}_{(k)}$ is the initial direction relation IF matrix of expert k.

$\tilde{\mathrm{z}}^{(\mathrm{k})}=\left[\begin{array}{cccc}0 & \tilde{\mathrm{z}}_{12}^{(\mathrm{k})} & \cdots & \tilde{\mathrm{z}}_{1 \mathrm{n}}^{(\mathrm{k})} \\ \tilde{\mathrm{z}}_{21}^{(\mathrm{k})} & 0 & \cdots & \tilde{\mathrm{z}}_{\mathrm{n}}^{(\mathrm{k})} \\ \vdots & \vdots & \ddots & \vdots \\ \tilde{\mathrm{z}}_{\mathrm{n} 1}^{(\mathrm{k})} & \tilde{\mathrm{z}}_{\mathrm{n} 2}^{(\mathrm{k})} & \cdots & 0\end{array}\right] ; \quad \mathrm{k}=1, \ldots, \mathrm{p}$
$\tilde{\mathrm{z}}_{\mathrm{ij}, \mathrm{TIFN}}^{(\mathrm{k})}=\left(\mathrm{l}_{\mathrm{ij}}^{(\mathrm{k})}, \mathrm{m}_{\mathrm{ij}}^{(\mathrm{k})}, \mathrm{u}_{\mathrm{ij}}^{(\mathrm{k})} ; \mathrm{l}_{\mathrm{ij}}^{\prime(\mathrm{k})}, \mathrm{m}_{\mathrm{ij}}^{(\mathrm{k})}, \mathrm{u}_{\mathrm{ij}}^{(\mathrm{k})}\right)$

\section{Step 4: Normalizing the direct-relation fuzzy matrix.}

The values of $\widetilde{\alpha}_{\mathrm{i}}^{(\mathrm{k})}$ and $\beta^{(k)}$ are the TIFNs as following Eq. (11) and Eq. (12).

$$
\begin{aligned}
& \widetilde{\alpha}_{\mathrm{i}}^{(\mathrm{k})}=\sum \widetilde{\mathrm{z}}_{\mathrm{ij}}^{(\mathrm{k})}=\left(\sum_{j=1}^{n} \mathrm{l}_{\mathrm{ij}}^{(\mathrm{k})}, \sum_{j=1}^{n} \mathrm{~m}_{\mathrm{ij}}^{(\mathrm{k})}, \sum_{j=1}^{n} \mathrm{u}_{\mathrm{ij}}^{(\mathrm{k})} ; \sum_{j=1}^{n} \mathrm{l}_{\mathrm{ij}}^{(\mathrm{k})}, \sum_{j=1}^{n} \mathrm{~m}_{\mathrm{ij}}^{(\mathrm{k})}, \sum_{j=1}^{n} \mathrm{u}_{\mathrm{ij}}^{(\mathrm{k})}\right) \\
& \beta^{(k)}=\max \left(\sum_{j=1}^{n} \mathrm{u}_{\mathrm{ij}}^{\prime(\mathrm{k})}\right) \quad 1 \leq i \leq n
\end{aligned}
$$


In addition, the linear scale transformation is used to transform the criteria scale into comparabale scales (Chou et al., 2012). Then we can get the normalized direct-relation IF matrix as $\widetilde{\mathrm{X}}^{(\mathrm{k})}$.

$\widetilde{\mathrm{X}}^{(\mathrm{k})}=\left[\begin{array}{cccc}\widetilde{\mathrm{X}}_{11}^{(\mathrm{k})} & \widetilde{\mathrm{X}}_{12}^{(\mathrm{k})} & \ldots & \widetilde{\mathrm{X}}_{1 \mathrm{n}}^{(\mathrm{k})} \\ \widetilde{\mathrm{X}}_{21}^{(\mathrm{k})} & \widetilde{\mathrm{X}}_{22}^{(\mathrm{k})} & \ldots & \widetilde{\mathrm{X}}_{2 \mathrm{n}}^{(\mathrm{k})} \\ \vdots & \vdots & \ddots & \vdots \\ \widetilde{\mathrm{X}}_{\mathrm{n} 1}^{(\mathrm{k})} & \mathrm{X}_{\mathrm{n} 2}^{(\mathrm{k})} & \ldots & \widetilde{\mathrm{X}}_{\mathrm{nn}}^{(\mathrm{k})}\end{array}\right] ; \quad \mathrm{k}=1, \ldots, \mathrm{p}$

$\tilde{\mathrm{z}}_{\mathrm{ij}, \mathrm{TIFN}}^{(\mathrm{k})}=\left(\mathrm{l}_{\mathrm{ij}}^{(\mathrm{k})}, \mathrm{m}_{\mathrm{ij}}^{(\mathrm{k})}, \mathrm{u}_{\mathrm{ij}}^{(\mathrm{k})} ; \mathrm{l}_{\mathrm{ij}}^{(\mathrm{k})}, \mathrm{m}_{\mathrm{ij}}^{(\mathrm{k})}, \mathrm{u}_{\mathrm{ij}}^{(\mathrm{k})}\right)$

where $\widetilde{\mathrm{X}}_{\mathrm{ij}}^{(\mathrm{k})}=\left(\frac{\tilde{\mathrm{z}}_{\mathrm{ij}}^{(\mathrm{k})}}{\beta^{(k)}}\right)=\left(\frac{\mathrm{l}_{\mathrm{ij}}^{(\mathrm{k})}}{\beta^{(k)}}, \frac{\mathrm{m}_{\mathrm{ij}}^{(\mathrm{k})}}{\beta^{(k)}}, \frac{\mathrm{u}_{\mathrm{ij}}^{(\mathrm{k})}}{\beta^{(k)}} ; \frac{\prime^{(\mathrm{kj})}}{\beta^{(k)}}, \frac{\mathrm{m}_{\mathrm{ij}}^{(\mathrm{k})}}{\beta^{(k)}}, \frac{\mathrm{u}_{\mathrm{ij}}^{(\mathrm{k})}}{\beta^{(k)}}\right)$.

This research assumes that at least one $i$ can be found such that $\sum_{j=1}^{n} \mathrm{u}_{\mathrm{ij}}^{\prime(\mathrm{k})}<\beta^{(k)}$. Furthermore, we use Eq. (11) and Eq. (12) to calculate the average matrix of $\widetilde{X}$.

$\widetilde{\mathrm{X}}=\frac{\widetilde{\mathrm{X}}^{(1)} \oplus \widetilde{\mathrm{X}}^{(2)} \oplus \ldots \oplus \widetilde{\mathrm{X}}^{(\mathrm{p})}}{\mathrm{p}}$

$\widetilde{\mathrm{X}}=\left[\begin{array}{cccc}\widetilde{\mathrm{X}}_{11} & \widetilde{\mathrm{X}}_{12} & \cdots & \widetilde{\mathrm{X}}_{1 \mathrm{n}} \\ \widetilde{\mathrm{X}}_{21} & \widetilde{\mathrm{X}}_{22} & \cdots & \widetilde{\mathrm{X}}_{2 \mathrm{n}} \\ \vdots & \vdots & \ddots & \vdots \\ \widetilde{\mathrm{X}}_{\mathrm{n} 1} & \widetilde{\mathrm{X}}_{\mathrm{n} 2} & \cdots & \widetilde{\mathrm{X}}_{\mathrm{nn}}\end{array}\right]$

where $\widetilde{\mathrm{X}}_{\mathrm{ij}}=\left(\sum_{k=1}^{p} x_{i j}^{(k)} / p\right)$.

Step 5: Establish and analyze the structural model.

Once the normalized direct-relation $X$ is obtained, the total-relation matrix $T$ can be calculated, we should ensure the convergence of $\lim _{w \rightarrow \infty} \widetilde{X}^{w}=0$. The total-relation IF matrix is shown as following Eqs. (16-18).

$\widetilde{T}=\lim _{w \rightarrow \infty}\left(\widetilde{\mathrm{X}}+\widetilde{\mathrm{X}}^{2}+\cdots+\widetilde{\mathrm{X}}^{\mathrm{w}}\right)$
$\widetilde{\mathrm{T}}=\left[\begin{array}{cccc}\tilde{\mathrm{t}}_{11} & \tilde{\mathrm{t}}_{12} & \ldots & \tilde{\mathrm{t}}_{1 \mathrm{n}} \\ \tilde{\mathrm{t}}_{21} & \tilde{\mathrm{t}}_{22} & \ldots & \tilde{\mathrm{t}}_{2 \mathrm{n}} \\ \vdots & \vdots & \ddots & \vdots \\ \tilde{\mathrm{t}}_{\mathrm{n} 1} & \tilde{\mathrm{t}}_{\mathrm{n} 2} & \ldots & \tilde{\mathrm{t}}_{\mathrm{nn}}\end{array}\right]$

where $\tilde{\mathrm{t}}_{\mathrm{ij}}=\left(\ddot{\mathrm{l}}_{\mathrm{ij}}, \ddot{\mathrm{m}}_{\mathrm{ij}}, \ddot{\mathrm{u}}_{\mathrm{ij}}, \ddot{\mathrm{l}}_{\mathrm{ij}}^{\prime}, \ddot{\mathrm{m}}_{\mathrm{ij}}, \ddot{\mathrm{u}}_{\mathrm{ij}}^{\prime}\right)$

$\operatorname{Matrix}\left[\ddot{\mathrm{l}}_{\mathrm{ij}}\right]=\widetilde{\mathrm{X}}_{\mathrm{l}} \times\left(\mathrm{I}-\widetilde{\mathrm{X}}_{\mathrm{l}}\right)^{-1}$

$\operatorname{Matrix}\left[\ddot{\mathrm{m}}_{\mathrm{ij}}\right]=\widetilde{\mathrm{X}}_{\mathrm{m}} \times\left(\mathrm{I}-\widetilde{\mathrm{X}}_{\mathrm{m}}\right)^{-1}$

$\operatorname{Matrix}\left[\ddot{\mathrm{u}}_{\mathrm{ij}}\right]=\widetilde{\mathrm{X}}_{\mathrm{u}} \times\left(\mathrm{I}-\widetilde{\mathrm{X}}_{\mathrm{u}}\right)^{-1}$

Matrix $\left[\tilde{\mathrm{l}}_{\mathrm{ij}}^{\prime}\right]=\widetilde{\mathrm{X}}_{\mathrm{l}}, \times\left(\mathrm{I}-\widetilde{\mathrm{X}}_{\mathrm{l}}\right)^{-1}$

$\operatorname{Matrix}\left[\ddot{\mathrm{u}}_{\mathrm{ij}}^{\prime}\right]=\widetilde{\mathrm{X}}_{\mathrm{u}} \times\left(\mathrm{I}-\widetilde{\mathrm{X}}_{\mathrm{u} \prime}\right)^{-1}$

\section{Step 6: Producing a casual diagram}

The sum of rows and the sum of columns are separately denoted as vector $\widetilde{D}_{i}$ and vector $\widetilde{R}_{i}$. We need to convert the IF number of vector $\widetilde{\mathrm{D}}_{\mathrm{i}}$ and vector $\widetilde{\mathrm{R}}_{\mathrm{i}}$ to the crisp value by applying Eq. (19). 
$\widetilde{D}_{i}^{\text {def }}=\frac{l_{i}+l_{i}^{\prime}+8 m_{i}+u_{i}+u_{i}^{\prime}}{12}$ for each $\widetilde{D}_{i}$

$\widetilde{\mathrm{R}}_{\mathrm{i}}^{\text {def }}=\frac{\mathrm{l}_{\mathrm{i}}+\mathrm{l}_{\mathrm{i}}^{\prime}+8 \mathrm{~m}_{\mathrm{i}}+\mathrm{u}_{\mathrm{i}}+\mathrm{u}_{\mathrm{i}}^{\prime}}{12}$ for each $\widetilde{\mathrm{R}}_{\mathrm{i}}$

The horizontal axis vector $\left(\widetilde{\mathrm{D}}_{i}^{\text {def }}+\widetilde{\mathrm{R}}_{i}^{\text {def }}\right)$ named "Prominence" is made by adding $\widetilde{\mathrm{D}}_{i}^{\text {def }}$ to $\widetilde{\mathrm{R}}_{i}^{\text {def }}$, which represents how much importance the criterion has.

Equally, the vertical axis $\left(\widetilde{\mathrm{D}}_{i}^{\text {def }}-\widetilde{\mathrm{R}}_{i}^{\text {def }}\right)$ named "Relation" is made by subtracting $\widetilde{\mathrm{D}}_{i}^{\text {def }}$ from $\widetilde{\mathrm{R}}_{i}^{\text {def }}$, by dividing criteria into a cause group and an effect group. Based on above statements, when $\left(\widetilde{\mathrm{D}}_{i}^{d e f}-\right.$ $\left.\widetilde{\mathrm{R}}_{i}^{\text {def }}\right)$ is positive, the criterion belongs to the cause group. Otherwise, the $\left(\widetilde{\mathrm{D}}_{i}^{\text {def }}-\widetilde{\mathrm{R}}_{i}^{\text {def }}\right)$ is negative, the criterion belongs to the effect group. Therefore, the casual diagram can be acquired by mapping the dataset of the $\left(\widetilde{\mathrm{D}}_{i}^{\text {def }}+\widetilde{\mathrm{R}}_{i}^{\text {def }}, \widetilde{\mathrm{D}}_{i}^{\text {def }}-\widetilde{\mathrm{R}}_{i}^{\text {def }}\right)$.

The importance of the criteria is calculated with the following equation:

$\omega_{\mathrm{i}}=\left\{\left(\widetilde{\mathrm{D}}_{i}^{\text {def }}+\widetilde{\mathrm{R}}_{i}^{\text {def }}\right)^{2}+\left(\widetilde{\mathrm{D}}_{i}^{\text {def }}-\widetilde{\mathrm{R}}_{i}^{\text {def }}\right)^{2}\right\}^{1 / 2}$

The importance of any criterion can be normalized as follows:

$\mathrm{W}_{\mathrm{i}}=\frac{\omega_{\mathrm{i}}}{\sum_{\mathrm{i}=1}^{\mathrm{n}} \omega_{\mathrm{i}}}$

where $W_{i}$ represents the final criteria weights to be used in thedecision making process (Dalalah et al., 2011). Consequently, as we use IF evaluations in Table 2 we come up with the weight vector of the criteria. After obtaining the $\mathrm{W}_{\mathrm{m}}$ vector of weights the relationship among the main criteria could be determined where $\mathrm{m}$ stands for main. The relationship among the criteria in each level of the hierarchy could be derived with the same method. In the case of the existence of sub-criteria, $\mathrm{W}_{\mathrm{s}}$ vector holds the weights of the sub-criteria. The $\mathrm{W}$ matrix, which represents the weights at the lowest level of the hierarchy is obtained by using the following equation (Baykasoğlu et al., 2013):

$w=\mathrm{W}_{\mathrm{m}} \mathrm{W}_{\mathrm{s}}$

\subsection{Integrating and ranking}

For each $\overline{\bar{w}}_{\mathrm{i}}$ obtained by IF-AHP, we can use same method to defuzzify TIFN (Eq. 24).

$\overline{\overline{\mathrm{w}}}_{\mathrm{i}}^{\mathrm{def}}=\frac{\mathrm{l}_{\mathrm{ij}}+\mathrm{l}_{\mathrm{ij}}^{\prime}+8 \mathrm{~m}_{\mathrm{ij}}+\mathrm{u}_{\mathrm{ij}}+\mathrm{u}_{\mathrm{ij}}^{\prime}}{12}$

Then the vector $\overline{\overline{\mathrm{w}}}$ should be aggregated with $w$ obtained by IF-DEMATEL method using any method of aggregation i.e. summation.

\section{Application of the proposed hybrid model: Managers selection in automobile industry in Iran}

Manager selection is a special case of selection. First an objective analysis of the required conditions should be performed. Then work should be adapted to individual needs and organizational planning. In addition the job sites should be evaluated and compared in such a way that about each of them can be treated fairly and equitably. In this paper we used the proposed model for selecting manager in automobile industrial in Iran. Consider the following hierarchy (Fig.1) for manager selection. Through the importance scale given in Table 1, a pairwise comparison is sought for the System Index with respect to the three criteria $\left(C_{j}, \mathrm{j}=1,2,3\right)$. Assume that the level of importance (or dominance) of $C_{2}$, over $C_{1}$, is a triangular IFS $\overline{\overline{3}}, C_{1}$ over $C_{3}$ is $\overline{\overline{2}}$, and $C_{2}$ over $C_{3}$ is $\overline{\overline{3}}$. Assume that $C_{1}$ is 
conceptual abilities, $\mathrm{C}_{2}$ is personal abilities, $\mathrm{C}_{3}$ is technical abilities. Hence, the judgment matrix is generated as follows:

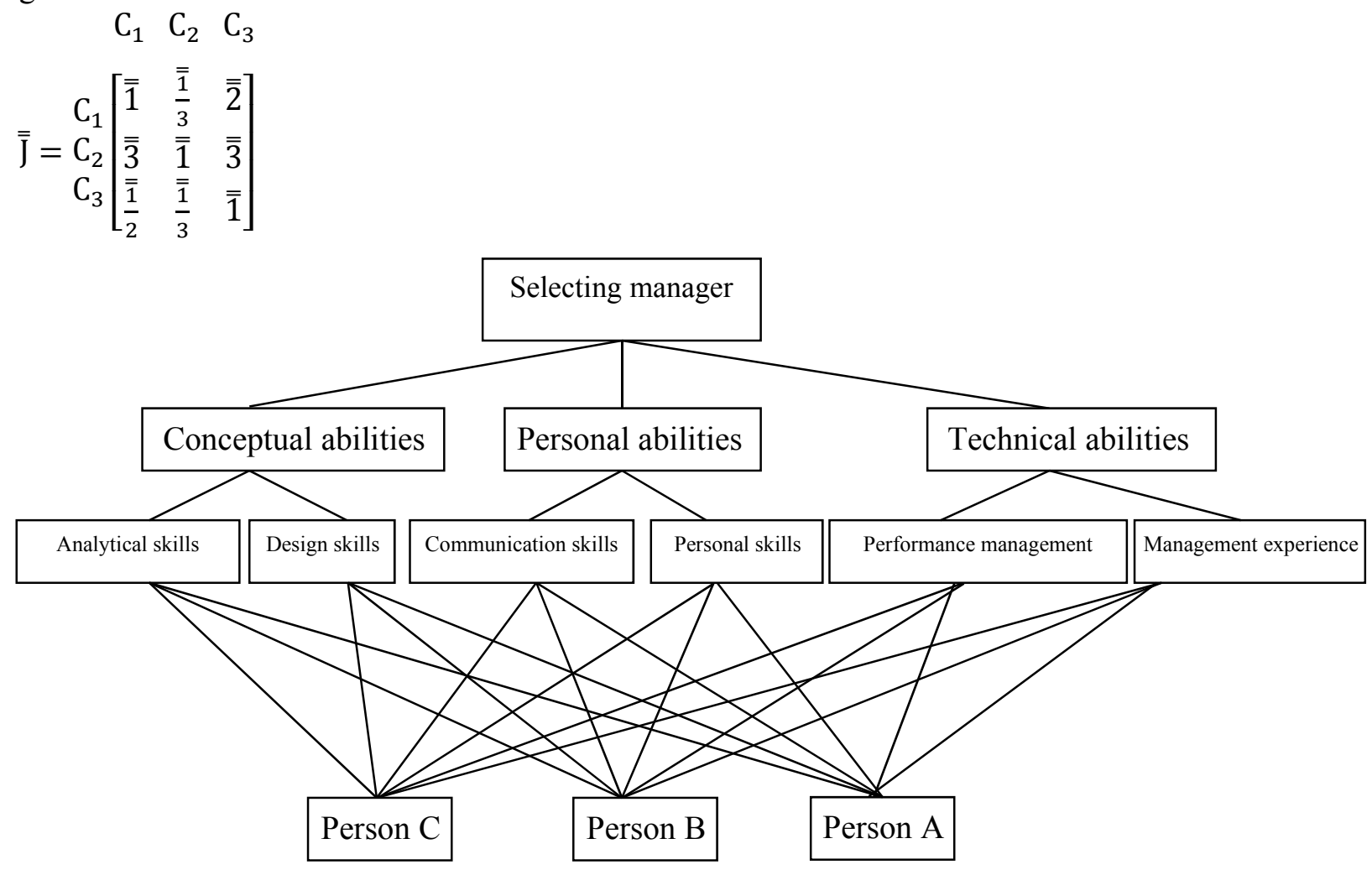

Fig. 1. hierarchy for manager selection

The interpretation of triangular IFS for each $\overline{\overline{\mathrm{J}}}_{\mathrm{ij}}$ is the same as defined earlier in this paper. For each $\overline{\bar{J}}_{\mathrm{ij}}$ we assume $\Delta^{\mu L}=0.5$ and $\Delta^{\mu U}=1$ for vagueness, and a membership interval of $[0.8,1.0]$ for nonspecificity. Similarly, for all alternatives, the pairwise comparisons are performed for each criterion based on qualitative importance rating provided in Table 1. For each criterion, calculations of the intuitionistic fuzzy weights $\overline{\overline{\mathrm{W}}}_{\mathrm{i}}$ are illustrated below:

$\overline{\overline{\mathrm{j}}}_{1}=\left(\overline{\overline{1}} \otimes \frac{\overline{\overline{1}}}{3} \otimes \overline{\overline{2}}\right)^{1 / 3}$

$=\left\langle\left[((1,1,1.5) \otimes 1 /(2.5,3,3.5) \otimes(1.5,2,3.5))^{1 / 3}, \min (0.8,0.8,0.8)\right],\left[((1,1,2) \otimes 1 /(2,3,4) \otimes(1,2,3))^{1 / 3}, \max (0,0,0)\right]\right\rangle$

$=\left\langle\left[((1,1,1.5) \otimes(1 / 3.5,1 / 3,1 / 2.5) \otimes(1.5,2,3.5))^{1 / 3}, 0.8\right],\left[((1,1,2) \otimes(1 / 4,1 / 3,1 / 2) \otimes(1,2,3))^{1 / 3}, 0\right]\right\rangle$

$\overline{\overline{\mathrm{J}}}_{2}=(\overline{\overline{3}} \otimes \overline{\overline{1}} \otimes \overline{\overline{3}})^{1 / 3}$

$=\left\langle\left[((2.5,3,3.5) \otimes(1,1,1.5) \otimes(2.5,3,3.5))^{1 / 3}, \min (0.8,0.8,0.8)\right],\left[((2,3,4) \otimes(1,1,2) \otimes(1,2,3))^{1 / 3}, \max (0,0,0)\right]\right\rangle$

$\overline{\overline{\mathrm{j}}}_{3}=(1 / \overline{\overline{2}} \otimes 1 / \overline{\overline{3}} \otimes \overline{\overline{1}})^{1 / 3}$

$=\left\langle\left[(1 /(1.5,2,2.5) \otimes 1 /(2.5,3,3.5) \otimes(1,1,1.5))^{1 / 3}, \min (0.8,0.8,0.8)\right],\left[(1 /(1,2,3) \otimes 1 /(2,3,4) \otimes(1,1,2))^{1 / 3}, \max (0,0,0)\right]\right\rangle$

$=\left\langle\left[((1 / 2.5,1 / 2,1 / 1.5) \otimes(1 / 3.5,1 / 3,1 / 2.5) \otimes(1,1,1.5))^{1 / 3}, 0.8\right],\left[((1 / 3,1 / 2,1) \otimes(1 / 4,1 / 3,1 / 2) \otimes(1,1,2))^{1 / 3}, 0\right]\right\rangle$

Thus, the intuitionistic fuzzy weight $\overline{\overline{\mathrm{w}}}_{\mathrm{i}}$ can be computed by normalizing the most likely value of $\overline{\overline{\mathrm{j}}}_{\mathrm{i}}$.

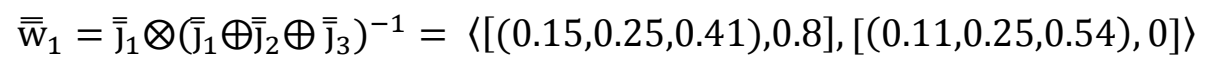

$\overline{\overline{\mathrm{w}}}_{2}=\overline{\overline{\mathrm{J}}}_{2} \otimes\left(\overline{\overline{\mathrm{J}}}_{1} \oplus \overline{\overline{\mathrm{J}}}_{2} \oplus \overline{\overline{\mathrm{J}}}_{3}\right)^{-1}=\langle[(0.39,0.59,0.88), 0.8],[(0.28,0.59,1.20), 0]\rangle$

$\overline{\overline{\mathrm{w}}}_{3}=\overline{\overline{\mathrm{J}}}_{3} \otimes\left(\overline{\overline{\mathrm{J}}}_{1} \oplus \overline{\overline{\mathrm{J}}}_{2} \oplus \overline{\overline{\mathrm{J}}}_{3}\right)^{-1}=\langle[(0.09,0.16,0.30), 0.8],[(0.08,0.16,0.38), 0]\rangle$ 
Sum of the most likely values of intuitionistic fuzzy weights, equals to $1(=0.25+0.59+0.16)$. Then we do all of these calculations for every comparison matrix obtained by decision makers. To summerize these numbers we use simple form of IFTN, as istance for $\overline{\overline{\mathrm{w}}}_{1}$ we write $(0.15,0.25,0.41 ; 0.11,0.25,0.54)$. Table 3 , Table 4 and Table 5 show weights of criteria and alternatives using AHP method (Here ND means the relation is not defined).

Table 3

Weights of criteria in level 2

\begin{tabular}{lcccc}
\hline & $\mathrm{C}_{1}$ & $\mathrm{C}_{2}$ & $\mathrm{C}_{3}$ & $\overline{\mathrm{w}}$ \\
\hline $\mathrm{C}_{1}$ & 1 & $1 / 3$ & 2 & $(0.15,0.25,0.41 ; 0.11,0.25,0.54)$ \\
$\mathrm{C}_{2}$ & 3 & 1 & 3 & $(0.39,0.59,0.88 ; 0.28,0.59,1.20)$ \\
$\mathrm{C}_{3}$ & $1 / 2$ & $1 / 3$ & 1 & $(0.09,0.16,0.30 ; 0.08,0.16,0.38)$ \\
\hline
\end{tabular}

\section{Table 4}

weights of criteria in level 3 regard to criteria in level 2.

\begin{tabular}{lccccccc}
\hline & $\mathrm{C}_{11}$ & $\mathrm{C}_{12}$ & $\mathrm{C}_{21}$ & $\mathrm{C}_{22}$ & $\mathrm{C}_{31}$ & $\mathrm{C}_{32}$ & $\overline{\overline{\mathrm{w}}}$ \\
\hline $\mathrm{C}_{11}$ & 1 & $1 / 3$ & $\mathrm{ND}$ & $\mathrm{ND}$ & $\mathrm{ND}$ & $\mathrm{ND}$ & $(0.15,0.22,0.30 ; 0.15,0.22,0.38)$ \\
$\mathrm{C}_{12}$ & 3 & 1 & $\mathrm{ND}$ & $\mathrm{ND}$ & $\mathrm{ND}$ & $\mathrm{ND}$ & $(0.55,0.78,0.82 ; 0.49,0.78,0.89)$ \\
$\mathrm{C}_{21}$ & $\mathrm{ND}$ & $\mathrm{ND}$ & 1 & 1 & $\mathrm{ND}$ & $\mathrm{ND}$ & $(0.34,0.5,0.66 ; 0.28,0.5,0.72)$ \\
$\mathrm{C}_{22}$ & $\mathrm{ND}$ & $\mathrm{ND}$ & 1 & 1 & ND & ND & $(0.34,0.5,0.66 ; 0.28,0.5,0.72)$ \\
$\mathrm{C}_{31}$ & $\mathrm{ND}$ & $\mathrm{ND}$ & $\mathrm{ND}$ & $\mathrm{ND}$ & 1 & 1 & $(0.34,0.5,0.66 ; 0.28,0.5,0.72)$ \\
$\mathrm{C}_{32}$ & $\mathrm{ND}$ & $\mathrm{ND}$ & $\mathrm{ND}$ & $\mathrm{ND}$ & 1 & 1 & $(0.34,0.5,0.66 ; 0.28,0.5,0.72)$ \\
\hline
\end{tabular}

Table 5

Weights of alternatives with regard to criteria in level 3

\begin{tabular}{cc}
\hline & \multicolumn{1}{c}{} \\
\hline $\mathrm{A}_{1}$ & $(0.20,0.22,0.28 ; 0.11,0.22,0.28)$ \\
$\mathrm{A}_{2}$ & $(0.30,0.41,0.51 ; 0.22,0.41,0.59)$ \\
$\mathrm{A}_{3}$ & $(0.28,0.37,0.43 ; 0.18,0.37,0.54)$ \\
\hline
\end{tabular}

In this step the matrix $\tilde{z}$ is obtained. $\tilde{z}$ matrix is built upon getting the linguistic assessment terms from the decision maker. Linguistic terms are given in Table 2. Table 5 shows the linguistic assessments of the decision maker on the relationship among the main criteria. For instance, "Design skills" has a considerable effect on "Analytical skills" criterion to according decision maker. Table 6 presents the assessment values of the linguistic evaluations of the decision maker. $\widetilde{\mathrm{X}}$ matrix is obtained by using the Eq. (13). Next, $\widetilde{T}$ matrix is obtained by using the Eq. (18). Table 8 shows final weights of alternatives that obtaind by aggregating AHP and DEMATEL.

Table 6

Assessment of the decision maker

\begin{tabular}{lcccccc}
\hline & $\mathrm{C}_{11}$ & $\mathrm{C}_{12}$ & $\mathrm{C}_{21}$ & $\mathrm{C}_{22}$ & $\mathrm{C}_{31}$ & $\mathrm{C}_{32}$ \\
\hline $\mathrm{C}_{11}$ & $\mathrm{O}$ & $\mathrm{H}$ & $\mathrm{L}$ & $\mathrm{VL}$ & $\mathrm{L}$ & $\mathrm{H}$ \\
$\mathrm{C}_{12}$ & $\mathrm{~L}$ & $\mathrm{O}$ & $\mathrm{NoN}$ & $\mathrm{VL}$ & $\mathrm{H}$ & $\mathrm{H}$ \\
$\mathrm{C}_{21}$ & $\mathrm{No}$ & $\mathrm{No}$ & $\mathrm{O}$ & $\mathrm{VH}$ & $\mathrm{H}$ & $\mathrm{H}$ \\
$\mathrm{C}_{22}$ & $\mathrm{VL}$ & $\mathrm{VL}$ & $\mathrm{VH}$ & $\mathrm{O}$ & $\mathrm{H}$ & $\mathrm{VH}$ \\
$\mathrm{C}_{31}$ & $\mathrm{No}$ & $\mathrm{No}$ & $\mathrm{L}$ & $\mathrm{L}$ & $\mathrm{O}$ & $\mathrm{H}$ \\
$\mathrm{C}_{32}$ & $\mathrm{VL}$ & $\mathrm{VL}$ & $\mathrm{L}$ & $\mathrm{H}$ & $\mathrm{H}$ & $\mathrm{O}$ \\
\hline
\end{tabular}

Table 7

Direct relation matrix

\begin{tabular}{|c|c|c|c|c|c|c|c|}
\hline & $\mathrm{C}_{11}$ & $\mathrm{C}_{12}$ & $\mathrm{C}_{21}$ & $\mathrm{C}_{22}$ & $\mathrm{C}_{31}$ & $\mathrm{C}_{32}$ & $\sum_{j=1}^{n} \mathrm{u}_{\mathrm{ij}}^{\prime(\mathrm{k})}$ \\
\hline$\overline{C_{11}}$ & $(0,0,0 ; 0,0,0)$ & $(5.5,6,6.5 ; 5,6,7)$ & $(3.5,4,4.5 ; 3,4,5)$ & $(1.5,2,2.5 ; 1,2,3)$ & $(3.5,4,4.5 ; 3,4,5)$ & $(5.5,6,6.5 ; 5,6,7)$ & 27 \\
\hline $\mathrm{C}_{12}$ & $(3.5,4,4.5 ; 3,4,5)$ & $(0,0,0 ; 0,0,0)$ & $(1,1,1 ; 1,1,1)$ & $(1,1,1 ; 1,1,1)$ & $(1.5,2,2.5 ; 1,2,3)$ & $(5.5,6,6.5 ; 5,6,7)$ & 17 \\
\hline $\mathrm{C}_{21}$ & $(1,1,1 ; 1,1,1)$ & $(1,1,1 ; 1,1,1)$ & $(0,0,0 ; 0,0,0)$ & $(7.5,8,8.5 ; 7,8,9)$ & $(5.5,6,6.5 ; 5,6,7)$ & $(5.5,6,6.5 ; 5,6,7)$ & 25 \\
\hline $\mathrm{C}_{22}$ & $(1.5,2,2.5 ; 1,2,3)$ & $(1.5,2,2.5 ; 1,2,3)$ & $(7.5,8,8.5 ; 7,8,9)$ & $(0,0,0 ; 0,0,0)$ & $(5.5,6,6.5 ; 5,6,7)$ & $(7.5,8,8.5 ; 7,8,9)$ & 31 \\
\hline $\mathrm{C}_{31}$ & $(1,1,1 ; 1,1,1)$ & $(1,1,1 ; 1,1,1)$ & $(3.5,4,4.5 ; 3,4,5)$ & $(3.5,4,4.5 ; 3,4,5)$ & $(0,0,0 ; 0,0,0)$ & $(5.5,6,6.5 ; 5,6,7)$ & 19 \\
\hline $\mathrm{C}_{32}$ & $(1.5,2,2.5 ; 1,2,3)$ & $(1.5,2,2.5 ; 1,2,3)$ & $(3.5,4,4.5 ; 3,4,5)$ & $(5.5,6,6.5 ; 5,6,7)$ & $(5.5,6,6.5 ; 5,6,7)$ & $(0,0,0 ; 0,0,0)$ & 25 \\
\hline
\end{tabular}


Table 9

Weights of alternatives

\begin{tabular}{|c|c|c|c|}
\hline & $\mathrm{A}_{1}$ & $\mathrm{~A}_{2}$ & $\mathrm{~A}_{3}$ \\
\hline $\mathrm{W}$ & 0.35 & 0.41 & 0.24 \\
\hline Rank & 2 & 1 & 3 \\
\hline
\end{tabular}

\section{Conclusion}

In view of the prominent advantage of IFS, a new IF-AHP-DEMATEL is proposed to deal with uncertainties in MCDM problems. For the purpose of practical applications of the proposed methodology, a step by step procedure has been presented in this study to facilitate idiographic operation of the potential users or DMs. Then the proposed method's code is written in MATLAB. Finally, a case study has been presented for manager selection in automobile industry in Iran and it has been analyzed. In this paper we used triangular numbers and sometimes calculations became complicated but we hope to use intuitionistc values instead of those kind of numbers in future studies.

\section{References}

Atanassov, K. (1986). Intuitionistic fuzzy sets. Fuzzy Sets and Systems, 20, 87-96.

Baykasoğlu, A., Kaplanoğlu, V., Durmuşoğlu, ZDU, Şahin, C. (2013). Integrating fuzzy DEMATEL and fuzzy hierarchical TOPSIS methods for truck selection. Expert Systems with Applications, 40(3), 899-907.

Buyukozkan, G., \& Cifci, G. (2011). A novel hybrid MCDM approach based on fuzzy DEMATEL, fuzzy ANP and fuzzy TOPSIS to evaluate green suppliers. Expert Systems with Applications, 39, 3000-3011.

Chang, B., Chang, C. W., \& Wu, C. H. (2011). Fuzzy DEMATEL method for developing supplier selection criteria. Expert Systems with Applications, 38, 1850-1858.

Chou, Y.C., Sun, C.C., \& Yen, H.Y. (2012). Evaluating the criteria for human resource for science and technology (HRST)based on an integrated fuzzy AHP and fuzzy DEMATEL approach. Applied Soft Computing, 2(1), 64-71.

Dalalah, D., Hayajneh, M., \& Batieha, F. (2011). A fuzzy multi-criteria decision making model for supplier selection. Expert Systems with Applications, 38, 8384-8391.

Jassbi, J., Mohamadnejad, F., \& Nasrollahzadeh, H. (2011). A Fuzzy DEMATEL framework for modeling cause and effect relationships of strategy map. Expert Systems with Applications, 38, 5967-5973.

Lin, C. J., \& Wu, W. W. (2008). A causal analytical method for group decision-making under fuzzy environment. Expert Systems with Applications, 34, 205-213.

Saaty, T.L., \& Shih, H.S. (2009). Structures in decision making: On the subjective geometry of hierarchies and networks. European Journal of Operational Research, 199, 867-872.

Saaty, T.L. (1980). The Analytic Hierarchy Process. McGraw Hill, New York.

Sadiq, R., \& Tesfamariam, S. (2009). Environmental decision-making under uncertainty using intuitionistic fuzzy analytic hierarchy process (IF-AHP).Stochastic Environmental Research and Risk Assessment, 23(1), 75-91.

Tseng, M. L. (2009). Using the extension of DEMATEL to integrate hotel service quality perceptions into a cause-effect model in uncertainty. Expert Systems with Applications, 36, 9015-9023.

Wang, H., Qian, G., \& Feg, X. (2011). An intuitionistic Fuzzy AHP Based on Synthesis of Eigenvectors and its Application. Information Technology Journal, 10(10), 1850-1866.

Wang, T.C., \& Chen, Y.H. (2008). Applying fuzzy linguistic preference relations to the improvement of consistency of fuzzy AHP. Information Sciences, 178, 3755-3765.

$\mathrm{Wu}, \mathrm{W}$. W., \& Lee, Y. T. (2007). Developing global managers' competencies using the fuzzy DEMATEL method. Expert Systems with Applications, 32, 499-507.

$\mathrm{Xu}, \mathrm{Z}$. (2007). Intuitionistic fuzzy aggregation operators. Fuzzy Systems, IEEE Transactions on, 15(6), 1179-1187.

Zadeh, L. A. (1965). Fuzzy sets. Information and control, 8(3), 338-353. 